\title{
$X$-ray diffraction studies of the growth of vanadium dioxide nanoparticles
}

\author{
S. A. Pauli, R. Herger, and P. R. Willmott \\ Swiss Light Source, Paul Scherrer Institute, CH-5232 Villigen, Switzerland \\ E. U. Donev, J. Y. Suh, and R. F. Haglund, Jr. ${ }^{\text {a) }}$ \\ Department of Physics and Astronomy and Vanderbilt Institute of Nanoscale Science and Engineering, \\ Vanderbilt University, Nashville, Tennessee 37235-1807, USA
}

(Received 20 May 2007; accepted 16 August 2007; published online 11 October 2007)

\begin{abstract}
We have characterized for the first time in situ the growth of vanadium dioxide nanoparticulate films prepared by pulsed-laser deposition, using a five-circle x-ray diffractometer, in order to provide structural information as the films are grown. A vanadium metal target was ablated in the presence of a pulsed $\mathrm{N}_{2} \mathrm{O}$ reactive gas source, and films were grown on $\mathrm{Si}(001)$ and $\mathrm{Al}_{2} \mathrm{O}_{3}(0001)$ substrates. Optical measurements confirmed that the films deposited in this way exhibit the well-known $\mathrm{VO}_{2}$ metal-insulator transition at approximately $70{ }^{\circ} \mathrm{C}$. The $\mathrm{VO}_{2}$ films grown at room temperature on silicon substrates are amorphous and extremely smooth. These become considerably rougher upon thermal annealing, as the $\mathrm{VO}_{2}$ phase crystallizes out in the form of hemispherical islands. These films also contain traces of a $\mathrm{V}_{2} \mathrm{O}_{5}$ nanoparticle phase in the first few monolayers, although the degree of $\mathrm{VO}_{2}$ crystallinity in the nanoparticles is quite high. In contrast, the $\mathrm{VO}_{2}$ nanoparticles grown on the sapphire substrates are in the form of preferentially oriented rodlike islands, with a maximum rod width of about $100 \mathrm{~nm}$. This in-plane texture is in keeping with the relatively good lattice match between film and substrate, indicating good potential for the growth of $\mathrm{VO}_{2}$ epitaxial films and single-crystal nanoparticles on such substrates. (C) 2007 American Institute of Physics.
\end{abstract} [DOI: $10.1063 / 1.2786917]$

\section{INTRODUCTION}

Transition-metal oxides are a fascinating class of materials in terms of the electronic and optical properties associated with their structural phase transitions. In particular, bulk vanadium oxides such as vanadium dioxide $\left(\mathrm{VO}_{2}\right)$ and vanadium sesquioxide $\left(\mathrm{V}_{2} \mathrm{O}_{3}\right)$ exhibit metal-insulator transitions (MITs) at different temperatures, depending on their stoichiometric phases. ${ }^{1,2}$ The metal-insulator transition in $\mathrm{VO}_{2}$ has recently aroused considerable interest for technological applications in optical switching, ${ }^{3}$ optical limiting, ${ }^{4}$ and thermal energy management ${ }^{5}$ because it occurs near ambient temperature, at approximately $340 \mathrm{~K}$, and can be manipulated by doping. Lopez et al. have reported that randomly distributed $\mathrm{VO}_{2}$ nanoparticles ${ }^{6}$ (NPs) and ordered, lithographically fabricated arrays of $\mathrm{VO}_{2} \mathrm{NPs}$ exhibit strongly enhanced linear ${ }^{7}$ and nonlinear ${ }^{8}$ optical response and MIT hysteresis widths, which are distinctively different from those of contiguous $\mathrm{VO}_{2}$ films. Epitaxial $\mathrm{VO}_{2}$ thin films have been shown to have potential applications in the millimeterwave portion of the electromagnetic spectrum, ${ }^{9}$ while $\mathrm{VO}_{2}$ NPs show an interesting plasmonic response in the vicinity of the near-infrared communications wavelengths. ${ }^{10}$ Vanadium dioxide could even conceivably have interesting thermomechanical properties owing to its ferroelasticity and negative stiffness. ${ }^{11}$ These varied potential applications have in turn motivated the search for efficient ways to fabricate high-quality, stoichiometric thin films and NPs of $\mathrm{VO}_{2}$.

However, the plethora of stable vanadium oxides, most

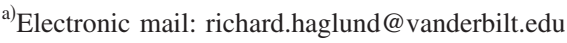

of which have no interesting phase transitions but whose phase diagrams are similar to those of $\mathrm{VO}_{2}$ and $\mathrm{V}_{2} \mathrm{O}_{3}$, means that stoichiometric growth of these oxides is a particular challenge. Pulsed-laser deposition ${ }^{12}$ (PLD) and radio frequency (rf)-magnetron sputtering ${ }^{13}$ of $\mathrm{VO}_{2}$ thin films were reported in the early 1990s. Most of the characterization studies in the literature concentrate on the properties of the films after a thickness of $100 \mathrm{~nm}$ or so has been reached; the only reference to epitaxial growth studies on sapphire as a function of film thickness used atomic-force microscopy to characterize morphology. ${ }^{14}$ A comparison of rf-magnetrongrown films on silicon and sapphire surfaces, using $\mathrm{x}$-ray diffraction, Rutherford backscattering, and electron microscopy, revealed columnar, polycrystalline growth on $\mathrm{Si}(100)$, but epitaxial growth on $\mathrm{Al}_{2} \mathrm{O}_{3} \cdot{ }^{13}$ More recently, it has been shown that growth conditions can affect the strain on $\mathrm{VO}_{2}$ thin films grown epitaxially on $\mathrm{TiO}_{2}{ }^{15}$

Accurate structural characterization of the first 10-20 $\mathrm{nm}$ of film deposition is particularly important for epitaxial film growth and growth of single-crystal NPs, as the filmsubstrate interface, including any potential lattice mismatch, plays a crucial role in the evolution of the epitaxial film, in strain-induced effects on the phase transition, and in the internal structure of the NPs. Because of the importance of the oxygen ambient in producing the correct stoichiometry of the $\mathrm{VO}_{2} \mathrm{NPs}$, it is noteworthy that in this PLD/x-ray diffraction (XRD) experiment, unlike any previously reported, the x-ray diffraction measurements were made in situ, so that those measurements would be guaranteed to reflect the structure of $\mathrm{VO}_{2}$ NPs essentially uncontaminated by other oxide phases. It has been found that $\mathrm{VO}_{2}$ crystallizes from its substoichio- 


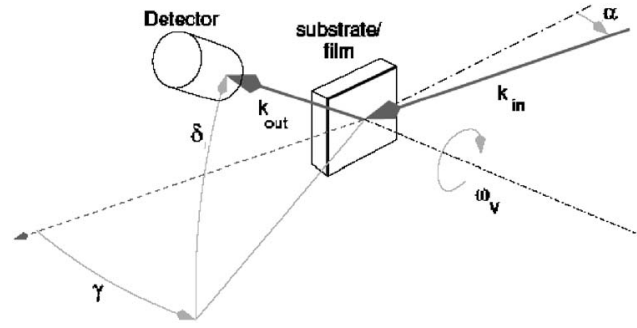

FIG. 1. A schematic of the relevant diffractometer angles. The incoming $\mathrm{X}$-ray beam impinges on the substrate/film at an angle $\alpha$. The position of the pixel detector is determined by $\gamma$, the horizontal (azimuthal) rotation away from the direct beam axis, and $\delta$, the polar angle. The sample can be rotated around its normal using the $\omega_{v}$ rotation. Positive angular movements are defined by the arrow heads.

metric phase at a temperature of hundreds of degrees Celsius. ${ }^{6,16}$ The degree of crystallization, which can be varied primarily by the processing conditions, is critical to the completion of the phase transition. Also, NPs can be formed in a natural manner, depending on the as-deposited material thickness and the substrate. In order to understand nanoparticle formation on the substrate surface of this prototypical strongly correlated electron system, as well as the relation between crystallographic phases and thermal treatment in vanadium oxides, we have carried out in situ XRD measurements during the pulsed-laser deposition and postannealing of $\mathrm{VO}_{2}$ on $\mathrm{Si}(001)$ and $\mathrm{Al}_{2} \mathrm{O}_{3}(0001)$ substrates.

In this article, $\mathrm{VO}_{2}$ nanoparticle formation, followed by further oxidation to $\mathrm{V}_{2} \mathrm{O}_{5}$, is evidenced by the emergence of the XRD signal of the relevant vanadium oxides, measured as a function of annealing time. This technique allows us to determine the vanadium-oxide phases present in our films and how they are affected by the presence of excess oxygen as the crystallization proceeds. In addition, the surface morphology of $\mathrm{VO}_{2}$ on the different substrates is investigated. While the $\mathrm{Si}$ substrate supports $\mathrm{VO}_{2}$ nanoparticles of hemispherical shape and no preferred in-plane crystallographic orientation, deposition on $\mathrm{Al}_{2} \mathrm{O}_{3}$ gives rise to the formation of rodlike islands arranged along the three equivalent crystal axes of the lattice-matched substrate. The optical reflection and transmission measurements as a function of sample temperature ensure that our $\mathrm{VO}_{2}$ films exhibit the requisite MIT switching characteristics.

\section{EXPERIMENTAL}

In situ XRD experiments were carried out using $16 \mathrm{keV}$ $(0.775 \AA)$ synchrotron radiation at the surface diffraction station of the Materials Science Beamline. ${ }^{17}$ The thin films were grown in a customized PLD/XRD ultrahigh vacuum chamber mounted on a five-circle surface diffractometer, described elsewhere. ${ }^{18}$ Diffraction signals were recorded using a two-dimensional pixel detector. ${ }^{19}$ The relevant angles of the diffractometer movements are shown in Fig. 1. Different scan modes are (1) in-plane 2 $\theta$ : $\alpha$ fixed and close to zero, $\delta$ scanned; (2) in-plane $\theta-2 \theta$ : $\alpha$ fixed and close to zero, $\delta$ scanned at twice the rate of $\omega_{v}$; (3) out-of-plane $2 \theta: \alpha$ fixed and close to zero, $\gamma$ scanned; (4) out-of-plane $\theta-2 \theta$ (reflectivity): $\gamma$ scanned at twice the rate of $\alpha$; and (5) azimuthal scan: $\delta$ fixed at a Bragg peak, $\omega_{v}$ scanned.
The $\mathrm{Si}(001)$ substrates were degassed at $325{ }^{\circ} \mathrm{C}$ for $2 \mathrm{~h}$ before being flashed at $900{ }^{\circ} \mathrm{C}$ for $30 \mathrm{~s}$ to remove the oxide layer. For growth on $\mathrm{Al}_{2} \mathrm{O}_{3}(0001)$, the substrates were degassed at $325{ }^{\circ} \mathrm{C}$ for $2 \mathrm{~h}$ before growth.

Films were grown by ablation of a vanadium rod target (diameter $12.7 \mathrm{~mm}$, purity $>99.9 \%$ ) in the presence of a synchronized $\mathrm{N}_{2} \mathrm{O}$ gas pulse. ${ }^{20}$ Films on $\mathrm{Si}(001)$ were grown at room temperature and annealed for times ranging up to a minute at a final temperature of $420{ }^{\circ} \mathrm{C}$. At that temperature, previous results ${ }^{16}$ show that the stoichiometry of the NPs is that of $\mathrm{VO}_{2}$; temperatures above $500{ }^{\circ} \mathrm{C}$ tend to encourage the growth of the $\mathrm{V}_{2} \mathrm{O}_{5}$ phase. Deposition on $\mathrm{Al}_{2} \mathrm{O}_{3}(0001)$ was performed either "hot" at $500 \pm 30{ }^{\circ} \mathrm{C}$, as in protocols reported in the literature, ${ }^{21}$ or at room temperature followed by an anneal at $500{ }^{\circ} \mathrm{C}$ for $60 \mathrm{~s}$ in $30 \mathrm{~Pa} \mathrm{O}_{2}$.

Scanning electron micrographs (SEMs) of grown films were recorded using a Zeiss Supra 55VP electron microscope, operating at $7 \mathrm{keV}$. Optical measurements as a function of temperature were performed at a laser wavelength of $1.3 \mu \mathrm{m}$; the temperature during these measurements was read by a thermocouple fixed in contact with the sample surface.

The optical measurements confirm the predominance of the $\mathrm{VO}_{2}$ phase, as evidenced by the relatively sharp changes in reflected [Fig. 2(a)] or transmitted [Fig. 2(b)] intensity upon cycling through the metal-insulator transition, and by the presence of thermal hystereses centered near the nominal transition temperature $\left(67^{\circ} \mathrm{C}\right)$. In general, the actual hysteresis sharpness, shape, width, position, and switching ratio depend, in various degrees, on the quality of the $\mathrm{VO}_{2}$ material (i.e., crystallinity, stoichiometry, impurities), the lateral grain $^{22}$ or nanoparticle ${ }^{23}$ size (through the availability of nucleating sites and the buildup of elastic stresses), the substrate material and its crystallographic orientation, and the film thickness. However, good switching characteristics are known to indicate a high degree of stoichiometry, as only a small deviation from "perfect" $\mathrm{VO}_{2}$ results in no switching at all. The optical curves in Fig. 2 thus show that our growth method can produce crystalline $\mathrm{VO}_{2}$ nanoparticles with good switching characteristics.

\section{RESULTS AND DISCUSSION}

The two substrates chosen for these deposition experiments were selected to allow comparisons between nanoparticle evolution on smooth surfaces with and without lattice matching. As will become apparent from the discussion, the $\mathrm{Si}(001)$ and $\mathrm{Al}_{2} \mathrm{O}_{3}(0011)$ surfaces used here lead to the evolution of crystalline $\mathrm{VO}_{2}$ nanoparticles in two distinct morphologies.

\section{A. Growth on $\mathrm{Si}(001)$}

Films deposited on $\mathrm{Si}(001)$ at room temperature showed no identifiable diffraction peaks, and only two very broad features, indicative of amorphous material. X-ray reflectivity curves (acquired by coordinated variation of $\alpha$ and $\gamma=2 \alpha$ ) indicated that despite their amorphous nature, the films were exceedingly flat, with roughness less than $0.4 \mathrm{~nm}$, even up to thicknesses in excess of $20 \mathrm{~nm}$ [see, for example, Fig. 3(a)]. 

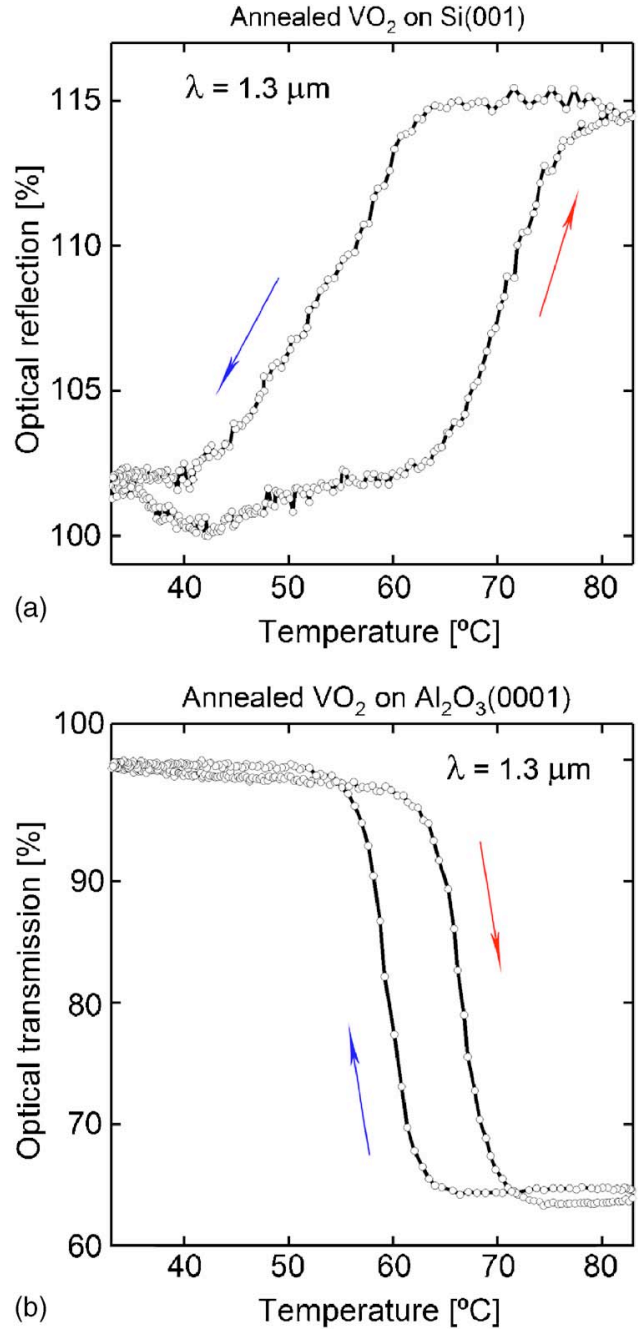

FIG. 2. (Color online) (a) Specular reflection and (b) normal-incidence transmission of $1.3 \mu \mathrm{m}$ laser light for annealed $\mathrm{VO}_{2}$ films grown on (a) silicon and (b) sapphire. In (a), the heating/cooling curve follows the up (red)/down (blue) arrow; the reflection, normalized to its lowest value in the insulating state, increases as the film is heated and becomes metallic. In (b), the heating/cooling curve follows the down (red)/up (blue) arrow; the transmission, normalized to its highest value in the insulating state, decreases as the film is heated and becomes metallic.

Annealing the film in $30 \mathrm{~Pa} \mathrm{O}_{2}$ at $420 \pm 25{ }^{\circ} \mathrm{C}$ resulted in the formation of the $\mathrm{VO}_{2}$ phase, in agreement with previous reports on PLD-grown $\mathrm{VO}_{2}{ }^{7,16}$ The formation of $\mathrm{VO}_{2}$ was monitored by sitting at the strongest powder diffraction peak $\left[\mathrm{VO}_{2}(011)\right.$ at $\left.\delta=13.8^{\circ}\right]$ and is shown in Fig. 4(a), while nearin-plane powder XRD survey scans $\left(\alpha=0.1^{\circ}, \gamma=0.2^{\circ}, \delta\right.$ scanned from $5^{\circ}$ to $50^{\circ}$ ) of the annealed and subsequently cooled film is shown in Fig. 4(b). The XRD signal did not change with rotation of the film around its normal axis $\left(\omega_{v}\right)$, demonstrating that the annealed film was polycrystalline with little or no texture. The $\mathrm{VO}_{2}$ phase would begin to transform to the highest oxidation state of vanadium, $\mathrm{V}_{2} \mathrm{O}_{5}$, if these annealing conditions were maintained for approximately $80 \mathrm{~s}$ or longer [as evident from the drop-off in intensity at the end of the time scan in Fig. 4(a)].

However, the effect of thermal expansion of the lattice on the position of the monitored $\mathrm{VO}_{2}(011)$ peak [Fig. 4(a)] must also be taken into account. A reasonable estimate of the
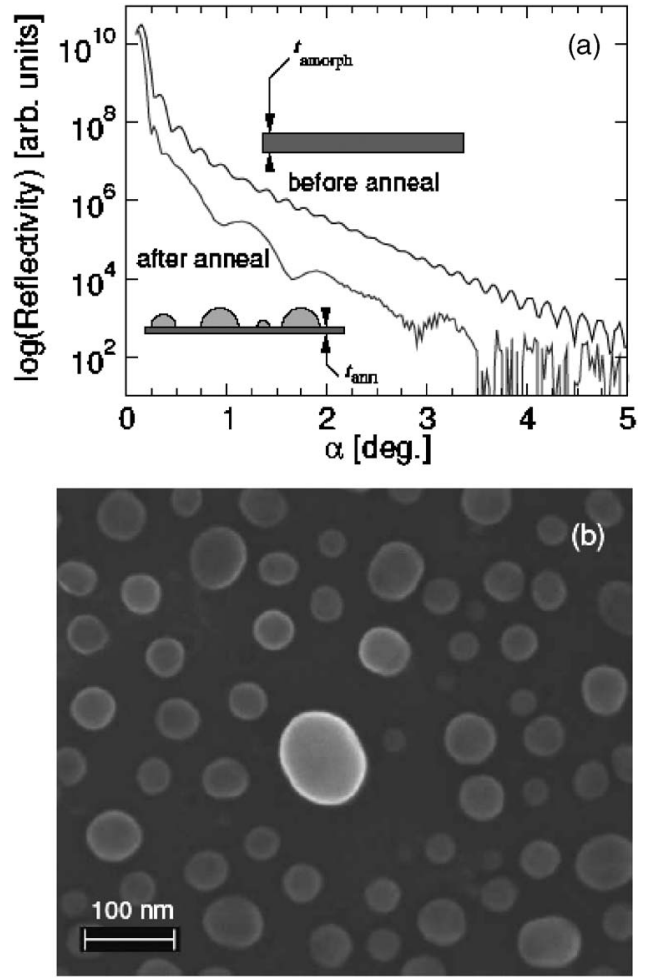

FIG. 3. Growth of $\mathrm{VO}_{2}$ on $\mathrm{Si}(001)$. (a) X-ray reflectivity curves of $\mathrm{VO}_{2}$ films and nanoparticles before and after annealing, respectively. From the Kiessig fringes and SEM images, it can be deduced that the atomically flat amorphous layer of thickness $t_{\text {amorph }}$ deposited at room temperature is mainly converted upon annealing into crystalline islands with a residual layer of thickness $t_{\mathrm{ann}}$. (b) SEM of an 11.6-nm-thick nanoparticulate $\mathrm{VO}_{2}$ film after annealing.

effect can be obtained from the following relationship, for a cubic lattice, between the coefficient of thermal expansion $\left(\alpha_{T}\right)$, the shift $(\Delta \theta)$ in the Bragg diffraction peak $\left(\theta_{B}\right)$, and the change in temperature $(\Delta T)$, namely ${ }^{24}$

$$
\Delta \theta=-\frac{\alpha_{T} \Delta T}{\cot \theta_{B}} .
$$

Substituting into Eq. (1) the largest value of $\alpha_{T}$ that we have found in the literature, ${ }^{25} \alpha_{T}=30 \times 10^{-6} \mathrm{~K}^{-1}$, together with $\Delta T=250 \mathrm{~K}$ [width of the "hump" in Fig. 4(a)] and $\theta_{B}$ $=\delta_{(011)}=13.8^{\circ}$, yields a value for the shift in the monitored peak of $\Delta \theta=-0.002^{\circ}$, well below our resolution of $0.015^{\circ}$. Therefore, thermal expansion of the sample during the temperature ramp cannot explain the observed decrease in the $\mathrm{VO}_{2}(011)$ signal with prolonged annealing time, so the formation of a $\mathrm{V}_{2} \mathrm{O}_{5}$ phase remains the likeliest possibility.

Accompanied by the formation of $\mathrm{VO}_{2}$ upon annealing was an apparent reduction in film thickness and increased film roughness [see the reflectivity curves in Fig. 3(a)]. SEM images showed the formation of hemispherical islands with diameters ranging from 10 to $100 \mathrm{~nm}$, essentially identical in form to those already reported in the literature. ${ }^{16}$ In addition, a broad but weak peak centered at $24^{\circ}$ grew in, which became more evident if the grazing incident angle $\alpha$ was increased from $0.1^{\circ}$ (below the critical angle of $\mathrm{VO}_{2}$ of $0.15^{\circ}$ ) to $0.5^{\circ}$. This peak could be tentatively ascribed to nanosized $\mathrm{V}_{2} \mathrm{O}_{5}$ particles. The in-plane size of these particles could be 

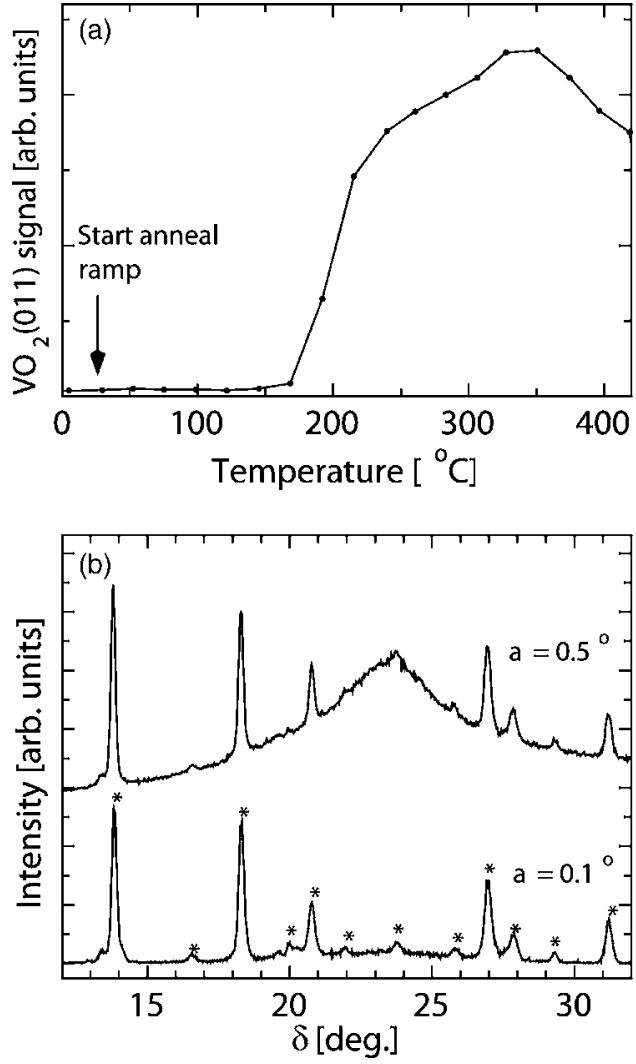

FIG. 4. (a) The $\mathrm{VO}_{2}(011)$ diffraction intensity from a film deposited on $\mathrm{Si}(001)$ as a function of time during the annealing ramp, which heated the sample from room temperature to $420{ }^{\circ} \mathrm{C}$ in $60 \mathrm{~s}$. Note that after approximately $50 \mathrm{~s}$, the signal begins to weaken, probably due to the formation of $\mathrm{V}_{2} \mathrm{O}_{5}$. (b) Near-in-plane powder XRD survey scans of the annealed film. All the peaks (marked with asterisks) could be attributed to $\mathrm{VO}_{2}$. With $\alpha$ $=0.5^{\circ}$ (above the critical angle of $0.15^{\circ}$ ), a broad signal at the Si-film interface could be sampled, which is tentatively attributed to nanocrystalline $\mathrm{V}_{2} \mathrm{O}_{5}$.

estimated from the Scherrer equation to be of the order of 0.8 $\mathrm{nm}$. Because this signal increases relative to the sharp $\mathrm{VO}_{2}$ peaks with the penetration depth of the incident $\mathrm{x}$ rays, we can be confident that these nanoparticles reside at the interface with the Si substrate. Interestingly, this signal does not increase further with continued annealing and appears to be "frozen in." The $\mathrm{V}_{2} \mathrm{O}_{5}$ peaks associated with prolonged annealing are always sharp and grow monotonically in intensity with annealing time, indicating that they rapidly form large in-plane domains with associated diffraction widths that are narrower than can be resolved with our incident x-ray beam divergence of $0.015^{\circ}$ in the plane of the sample . From the Scherrer equation, this implies in-plane domain sizes in excess of $300 \mathrm{~nm}$.

Why should the film appear to become thinner upon annealing? Reevaporation can be discounted due to the negligible vapor pressures of $\mathrm{V}$ and $\mathrm{VO}_{2}$ at these modest temperatures. SEM images confirm the evidence from the $\mathrm{x}$-ray reflectivity and diffraction measurements: These images reveal that the morphology of the film changes from a smooth, amorphous, and continuous film as deposited to a twodimensional layer of crystalline islands after annealing. Consider Fig. 3(b); it depicts a SEM of an annealed film with $t_{\text {amorph }}=11.6 \mathrm{~nm}$ in the amorphous (as-deposited) state. The thickness of the remaining layer underneath the islands is difficult to determine accurately from the Kiessig fringes, due to the increased roughness and shadowing of the reflectivity signal by the crystalline islands, but is estimated to be $t_{\mathrm{ann}}=3.7 \pm 0.4 \mathrm{~nm}$. If we ignore any differences in mass density among the initial amorphous layer, the islands, and the remaining underlayer, then conservation of mass dictates that

$$
t_{\text {amorph }}=t_{\text {ann }}+\frac{2 r f}{3},
$$

where $r$ is the average island radius, $f$ is the fractional areal coverage of the islands, and where we have assumed that the islands are perfect hemispheres. Image processing of Fig. 3 (b) yields $f=0.34 \pm 0.02$, while the average island radius was calculated from a sample set of 40 to be $31 \pm 5 \mathrm{~nm}$. Inserting these values into Eq. (2), we obtain $t_{\text {ann }}$ $=4.6 \pm 0.8 \mathrm{~nm}$, which agrees well with the experimentally determined value within the estimated errors.

The chemical and crystallographic composition of the underlying thin layer remains uncertain. It is speculated that it is most likely the remainder of a "reservoir" of the amorphous material that was initially deposited at room temperature and has not been fully depleted before the $\mathrm{V}_{2} \mathrm{O}_{5}$ phase begins to form. Indeed, further annealing results in a small reduction in this thickness, although within the maximum integrated anneal times of $10 \mathrm{~min}$, the layer still remains, which may be due to kinetic hindering of island ripening as the reservoir becomes more and more depleted.

\section{B. Growth on $\mathrm{Al}_{2} \mathrm{O}_{3}(0001)$}

Growth of $\mathrm{VO}_{2}$ on sapphire was performed under conditions similar to those described by Garry et al. ${ }^{21}$ whereby the main difference was the use of the synchronized $\mathrm{N}_{2} \mathrm{O}$ pulse instead of a constant background pressure of $\mathrm{O}_{2}$. Deposition at room temperature followed by annealing at $500{ }^{\circ} \mathrm{C}$ produced the same quality films as those grown at $500{ }^{\circ} \mathrm{C}$ without annealing.

In-plane XRD scans showed the films to be strongly textured and were dominated by $(n 00)$ signals, with $n=1,2,3$, although there were also minor contributions from the (304), $(\overline{1} 04)$, and $(\overline{3} 24) /(\overline{5} 02)$ phases. Because of this texturing, $2 \theta$ scans (i.e., movement of $\delta$ only) were insufficient and $\theta$ $-2 \theta$ scans (i.e., movement of both $\omega_{v}$ and $\delta=2 \omega_{v}$ ) were necessary. Azimuthal scans (movement of $\omega_{v}$ only, with $\delta$ positioned at an in-plane Bragg peak) demonstrated textured growth and the locking into the hexagonal close-packed symmetry of the underlying $\mathrm{Al}_{2} \mathrm{O}_{3}(0001)$ substrate surface. For example, the $\mathrm{VO}_{2}(100)$ signal consists of doublets every $60^{\circ}$. From a prior knowledge of the orientation of the sapphire substrates, it can be deduced that the twinned $\mathrm{VO}_{2}(100)$ planes are $2.6^{\circ}$ to each side of the sapphire

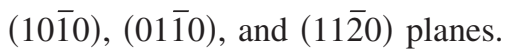

The doublet separation of $5.2^{\circ}$ [Fig. 5(a)] can be explained as follows; consider Fig. 5(b). At room temperature, monoclinic $\mathrm{VO}_{2}$ has an angle $\beta=122.60^{\circ}$ between the $a$ and $c$ axes. Due to the chiral symmetry of monoclinic crystals, the (100) planes of the enantiomeric twins can lock onto any 

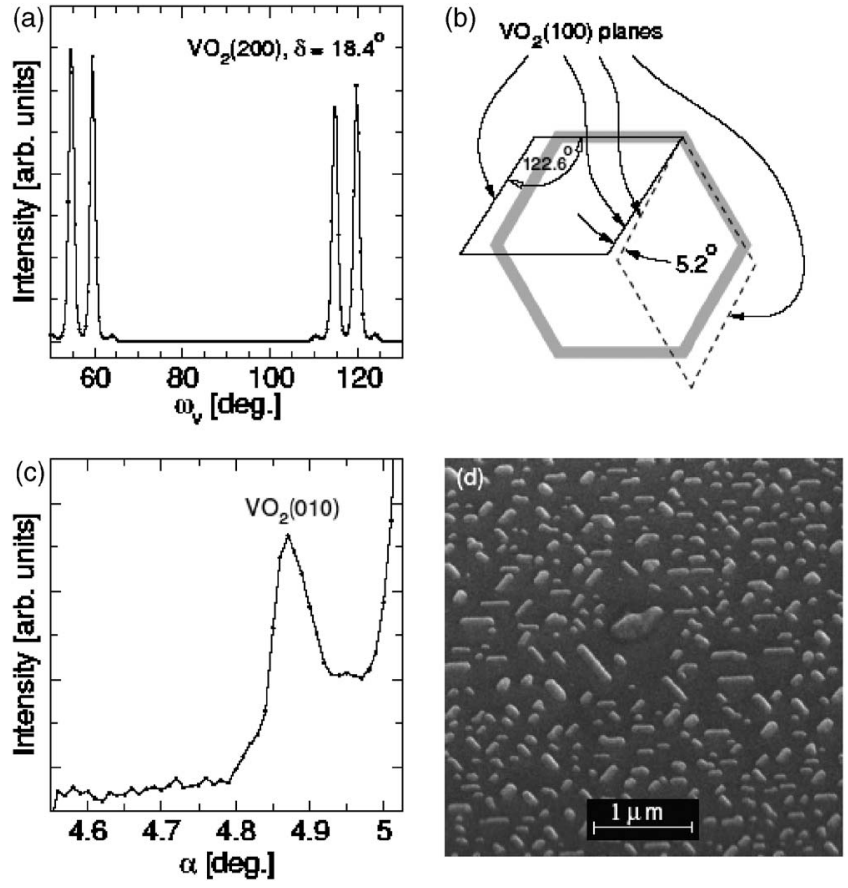

FIG. 5. Growth of $\mathrm{VO}_{2}$ on $\mathrm{Al}_{2} \mathrm{O}_{3}(0001)$. (a) Azimuthal near-in-plane scan of the $\mathrm{VO}_{2}$ diffraction signal, indicating strongly textured film growth, with sixfold in-plane symmetry. (b) Schematic showing the locking-in of the $\mathrm{VO}_{2}$ in-plane orientation to the underlying sapphire(0001) substrate. (c) A consequence of the $\mathrm{VO}_{2}(100)$ planes being perpendicular to the film surface is the fact that the $\mathrm{VO}_{2}(010)$ planes are parallel to the surface. The associated XRD signal in a $\theta-2 \theta$ scan is shown here, on the low-angle flank of the strong sapphire(0003) substrate signal. (d) SEM of the oriented $\mathrm{VO}_{2}$ crystallites.

of the sapphire $(10 \overline{10}),(01 \overline{1} 0)$, and (1120) planes, their separations being equal to twice the difference between $\beta$ and $120^{\circ}{ }^{26}$

This locking-in to the sapphire surface is manifested by the morphology of the $\mathrm{VO}_{2}$ islands. Figure 5(d) shows SEM images of these islands, which, after growth of $5.3 \mathrm{~nm} \mathrm{VO}$, clearly exhibit pyramidal facets oriented along three equivalent axes separated by $120^{\circ}$. Those islands with lateral dimensions not exceeding approximately $100 \mathrm{~nm}$ appear to have a more or less isotropic shape. Once the islands grow past this critical size, they begin to assume a distinctive rodlike appearance, indicative of uniaxial strain relaxation at this width, which thereby breaks the symmetry and allows further lateral growth in only one direction. This anisotropic growth and formation of nanoscale rodlike structures may have important consequences for light-induced, ultrafast, and polarization-dependent MIT phase transitions, similar to that recently reported by Lysenko et al. ${ }^{27}$

The strong texturing of the films was confirmed by the presence of only the $\mathrm{VO}_{2}(010)$ reflection, in out-of-plane $\theta$ $-2 \theta$ scans, shown in Fig. 5(c). The $\mathrm{VO}_{2}(010)$ plane is perpendicular to the $(n 00)$ planes.

\section{CONCLUDING REMARKS}

In conclusion, we have observed in situ the growth of nanoparticulate vanadium dioxide using synchrotron-based $\mathrm{x}$-ray diffraction. The good quality of the films was ascertained by optical measurements of the thermal hysteresis across the $\mathrm{VO}_{2}$ metal-insulator transition. Films grown at room temperature and on $\mathrm{Si}(001)$ are amorphous and very flat, and only crystallize into the $\mathrm{VO}_{2}$ phase upon thermal annealing in a background of $\mathrm{O}_{2}$. This crystallization is accompanied by a significant roughening of the film morphology as the crystalline phase forms nanosized hemispherical islands that show no preferential orientation with respect to the substrate crystallography. In contrast, ultrathin layers of $\mathrm{VO}_{2}$ grown on $\mathrm{Al}_{2} \mathrm{O}_{3}$ form twinned, elongated, rodlike islands oriented along the three equivalent in-plane crystallographic axes of the $\mathrm{Al}_{2} \mathrm{O}_{3}(0001)$ surface. The width of the islands appears to be limited to approximately $100 \mathrm{~nm}$, and the distribution of island shapes indicates that the growth is isotropic up to this size, after which uniaxial strain relaxation forces the islands to ripen further in only one direction. This may have important technological consequences for polarization-dependent and light-induced metal-insulator phase transitions.

\section{ACKNOWLEDGMENTS}

The authors thank Anja Weber for assistance in recording the SEM images. Research at Vanderbilt was supported by a Nanoscience Interdisciplinary Research Team grant from the National Science Foundation (DMR-0210785). P.R.W., R.H., and S.A.P. gratefully acknowledge support of this work by the Schweizerischer Nationalfonds zur Förderung der Wissenschaftlichen Forschung and the staff of the Swiss Light Source. Part of this work was performed at the Swiss Light Source, Paul Scherrer Institute.

${ }^{1}$ F. J. Morin, Phys. Rev. Lett. 3, 34 (1959).

${ }^{2}$ D. Adler, J. Feinleib, H. Brooks, and W. Paul, Phys. Rev. 155, 851 (1967).

${ }^{3}$ M. F. Becker, A. B. Buckman, R. M. Walser, T. Lepine, P. Georges, and A. Brun, J. Appl. Phys. 79, 2404 (1996).

${ }^{4}$ J. F. Xu, R. Czerw, S. Webster, D. L. Carroll, J. Ballato, and R. Nesper, Appl. Phys. Lett. 81, 1711 (2002).

${ }^{5}$ T. D. Manning, I. P. Parkin, M. E. Pemble, D. Sheel, and D. Vernardou, Chem. Mater. 16, 744 (2004).

${ }^{6}$ R. Lopez, L. A. Boatner, T. E. Haynes, L. C. Feldman, and R. F. Haglund, Jr., J. Appl. Phys. 92, 4031 (2002).

${ }^{7}$ R. Lopez, L. C. Feldman, and R. F. Haglund, Jr., Phys. Rev. Lett. 93, 177403 (2004).

${ }^{8}$ R. Lopez, L. C. Feldman, R. F. Haglund, Jr., T. E. Haynes, and L. A. Boatner, Appl. Phys. Lett. 85, 5191 (2004).

${ }^{9}$ P. F. Hood and J. F. DeNatale, J. Appl. Phys. 70, 376 (1991).

${ }^{10}$ M. Rini, A. Cavelleri, R. W. Schoenlein, R. Lopez, L. C. Feldman, R. F. Haglund, Jr., L. A. Boatner, and T. E. Haynes, Opt. Lett. 30, 558 (2005).

${ }^{11}$ R. S. Lakes, T. Lee, A. Bersie, and Y. C. Wang, Nature (London) 410, 565 (2001).

${ }^{12}$ V. N. M. Borek, F. Quian, and R. K. Singh, Appl. Phys. Lett. 63, 3288 (1993).

${ }^{13}$ M. C. L. K. D. Rogers and J. A. Roath, J. Appl. Phys. 70, 1412 (1991).

${ }^{14}$ G. Xu, P. Jin, M. Tazawa, and K. Yoshimura, Appl. Surf. Sci. 244, 449 (2005).

${ }^{15}$ K. Nagashima, T. Namagida, H. Tanaka, and T. Kawai, J. Appl. Phys. 100, 063714 (2006).

${ }^{16}$ J. Y. Suh, R. Lopez, L. C. Feldman, and R. F. Haglund, Jr., J. Appl. Phys. 96, 1209 (2004).

${ }^{17}$ B. D. Patterson, R. Abela, H. Auderset, Q. Chen, F. Fauth, F. Gozzo, G. Ingold, H. Kühne, M. Lange, D. Maden, D. Meister, P. Pattison, Th. Schmidt, B. Schmitt, C. Schulze-Briese, M. Shi, M. Stampanoni, and P. R. Willmot, Nucl. Instrum. Methods Phys. Res. A 540, 42 (2005).

${ }^{18}$ P. R. Willmott, C. M. Schlepütz, B. D. Patterson, R. Herger, M. Lange, D. Meister, D. Maden, C. Brönnimann, E. F. Eikenberry, G. Hülsen, and A. Al-Adwan, Appl. Surf. Sci. 247, 188 (2005).

${ }^{19}$ C. M. Schlepütz, R. Herger, P. R. Willmott, B. D. Patterson, O. Bunk, C. 
Brönnimann, B. Henrich, G. Hülsen, and E. F. Eikenberry, Acta Crystallogr., Sect. A: Found. Crystallogr. A61, 418 (2005).

${ }^{20}$ P. R. Willmott, R. Timm, P. Felder, and J. R. Huber, J. Appl. Phys. 76, 2657 (1994).

${ }^{21}$ Z. P. Wu, S. Yamamoto, A. Miyashita, Z. J. Zhang, K. Narumi, and H. Naramoto, J. Phys.: Condens. Matter 10, L765 (1998).

${ }^{22}$ R. A. Aliev, V. N. Andreev, V. M. Kapralova, V. A. Klimov, A. I. Sobolev, and E. B. Shadrin, Phys. Solid State 48, 929 (2006).

${ }^{23}$ R. Lopez, T. E. Haynes, L. A. Boatner, L. C. Feldman, and R. F. Haglund,
Jr., Phys. Rev. B 65, 224113 (2002).

${ }^{24}$ T. L. Alford, L. C. Feldman, and J. W. Mayer, Fundamentals of Nanoscale Film Analysis (Springer, New York, 2007).

${ }^{25}$ Non-Tetrahedrally Bonded Binary Compounds II (Springer, Berlin, 2000), Vol. 41D, Chap. VO2, pp. 1-2.

${ }^{26}$ G. Garry, O. Durand, and A. Lordereau, Thin Solid Films 453-454, 427 (2004).

${ }^{27}$ S. Lysenko, V. Vikhnin, F. Fernandez, A. Rua, and H. Liu, Phys. Rev. B 75, 075109 (2007). 